\title{
A RETROSPECTIVE DESCRIPTIVE STUDY OF EPIDEMIOLOGY OF FRACTURES OF ZYGOMA IN TERTIARY CARE HOSPITAL OVER A PERIOD OF A DECADE
}

\author{
Pokkula Ramesh ${ }^{1}$ Erugurala Mahendar², Arige Subodh Kumar 3 , M. Arjun Reddy ${ }^{4}$,Challuri Anita 5
}

${ }^{1}$ Associate Professor, Department of Plastic Surgery, Gandhi Medical College, Secunderbad, Telangana, India. ${ }^{2}$ Assistant Professor, Department of Plastic Surgery, Gandhi Medical College, Secunderbad, Telangana, India. 3 Professor and HOD, Department of Plastic Surgery, Gandhi Medical College, Secunderbad, Telangana, India. 4 Senior Resident, Department of Plastic Surgery, Gandhi Medical College, Secunderbad, Telangana, India. ${ }^{5}$ Associate Professor, Department of Biochemistry, Osmania Medical College, Hyderabad, Telangana, India.

\section{ABSTRACT}

\section{BACKGROUND}

Zygoma is a very crucial component, which maintains facial contour. Fracture and dislocation of this bone not only causes cosmetic defects, but also disrupts ocular and mandibular functions. Fractures can involve any of the four articulations of zygoma, which include zygomaticomaxillary complex, zygomatic complex and orbitozygomatic complex. Management depends on a thorough preoperative physical examination with special attention to the ophthalmologic assessment. Fractures involving zygoma should be repaired at the earliest, because it can cause both functional and cosmetic defects. These fractures are common in our institution and a study is being undertaken to study the causes, pattern of fractures, the diagnostic and treatment modalities adopted.

The aim of this study is to analyse the cause, age and gender, incidence, sites of fracture of zygoma, various combinations of fractures, diagnostic and treatment modalities that were used.

\section{MATERIALS AND METHODS}

This retrospective descriptive study includes 366 patients with fractures of zygoma treated in the Department of Plastic Surgery at Gandhi Medical College between the years 2008 - 2017. The history obtained, clinical examination and diagnostic tests done were analysed. Incidence, age, gender, site of fracture, side of fracture, aetiology and method of management and the outcome after surgery were the different variables analysed.

\section{RESULTS}

366 patients with fractures of zygoma were analysed. There is a rise of incidence ranging from as low as $12.96 \%$ to as high as $62.50 \%$ of total fracture of faciomaxillary cases during the decade. Males were more frequently involved (88.79\%) in comparison to females. The commonly involved age group was between 21 - 30 years (36.88\%). Most of the patients sustained injuries due to road traffic accidents (78.14\%). Body of the zygoma was involved in 33.33\% of total cases of fracture zygoma cases. X-rays, digital $\mathrm{x}$-rays and 3D computerised tomography were used as the diagnostic modalities. Open reduction and internal fixation with plate and screws was done in $50.27 \%$ of cases. Complications like wound infection, plate exposure were noted in $8.46 \%$ (31 out of 366 patients).

\section{CONCLUSION}

Road traffic accidents were found to be the common cause of fractures of the zygoma. Awareness regarding traffic rules and regulations and counselling youth regarding hazards of drunken driving, bike and car races on public roads should to be done. In young males, body of the zygoma was more commonly involved. Early intervention enabled good functional and aesthetic outcomes. Patients with restricted mouth opening can be attended to by either redo-ORIF or dilatations with Heister's dilator or by insertion of the ice cream sticks by increasing them progressively.

\section{KEY WORDS}

Zygoma Fracture, Arch Fracture, RTA, ORIF, Gillies' Elevation, Restricted Mouth Opening.

HOW TO CITE THIS ARTICLE: Ramesh P, Mahendar E, Kumar AS, et al. A retrospective descriptive study of epidemiology of fractures of zygoma in tertiary care hospital over a period of a decade. J. Evolution Med. Dent. Sci. 2018;7(34):3766-3770, DOI: $10.14260 /$ jemds $/ 2018 / 846$

\section{BACKGROUND}

Zygoma is a very crucial component, which maintains facial contour. This is because the facial contour is directly influenced by underlying architecture. ${ }^{1}$

'Financial or Other Competing Interest': None.

Submission 11-07-2018, Peer Review 04-08-2018,

Acceptance 10-08-2018, Published 20-08-2018.

Corresponding Author:

Dr. Pokkula Ramesh,

H. No. 1-31-832/1, Krishna Enclave,

Indira Nagar, Military Dairy Road,

Trimulgherry, Secunderabad-500015, Telangana, India

E-mail: drrameshps2505@gmail.com

DOI: $10.14260 /$ jemds $/ 2018 / 846$
The zygomatic region is a prominent portion of the face next to the dorsum of the nose. This predisposes this bone to various trauma. ${ }^{2}$ The bony architecture of this bone is unique. It enables it to withstand blows with significant impact without being fractured. At the most, it gets disarticulated along its suture lines. Fractures can involve any of the four articulations of zygoma, which include zygomaticomaxillary complex, zygomatic complex and orbitozygomatic complex. Management depends on a thorough preoperative physical examination with special attention to the ophthalmologic assessment. ${ }^{3}$ Fractures involving zygoma should be repaired at the earliest, because it can cause both functional and cosmetic defects. Traditionally, in the assessment of the reduction of zygomatic arch fractures, the surgeon uses 
subjective measures such as palpation of a bony step deformity, the anecdotal "pop" sounds and visual confirmation of symmetry. 4

The zygomaticomaxillary complex functions as the principle buttress of the face and is the cornerstone to an individual's aesthetic appearance. Its fracture not only creates cosmetic deformities owing to its position and facial contour, but can also cause disruption of ocular and mandibular functions. ${ }^{5}$ Important functional defects involving this bone is restriction of mouth opening due to impingement on the coronoid process. ${ }^{6}$

It is hence mandatory to diagnose and treat this condition properly. It is also important to reduce this fracture and fix it accurately, because skeletal healing after inadequate reduction can cause reduced projection of malar region of the face leading on to cosmetic deformities. Accurate assessment of position of the fractured bone should be performed in relation to skull base posteriorly and mid-face anteriorly. This assessment is very important before reduction is attempted to ensure accurate reduction of the fractured fragments. ${ }^{7}$

\section{MATERIALS AND METHODS}

We did a retrospective descriptive study of all patients who were admitted and treated for facial trauma during the period between 2008 - 2017. All the patients with zygoma fractures have been included in our study. Those excluded from the study were patients with,

1. Age below 10 years and above 70 years.

2. Patients with polytrauma.

3. Unstable patients with neurological problems.

All faciomaxillary fracture patients were initially admitted in trauma care ward. After they got stabilised, they were shifted to the Department of Plastic Surgery. Diagnosis was made on the basis of clinical examination and radiological examination. The data was analysed based on age, sex, site (anatomical distribution), side, aetiology and management.

\section{RESULTS}

During these ten years period between 2008 - 2017, faciomaxillary injuries were 1046 and patients with zygoma fractures were 366 (Chart 1).

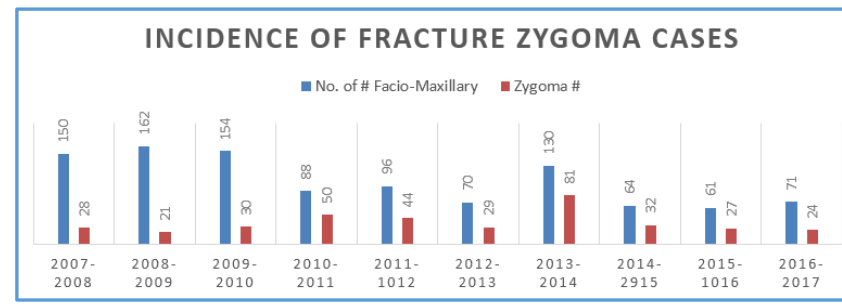

Chart 1. Showing Incidence of Fracture Zygoma Cases

Males were more commonly involved and accounted for $88.79 \%$, while females constituted $11.21 \%$ as shown in Chart 2.

\section{GENDER DISTRIBUTION}

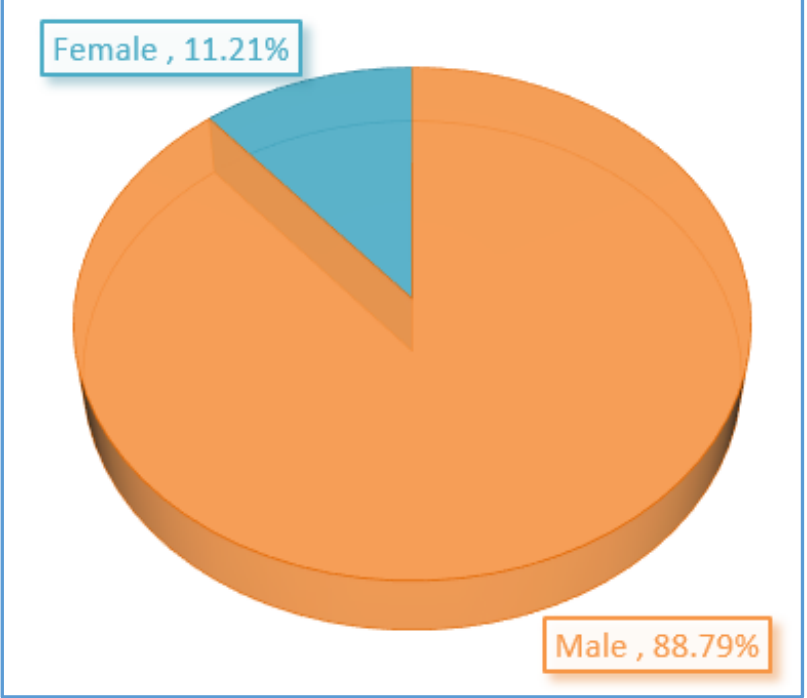

Chart 2. Showing Gender Distribution

The most affected age group was 21 - 30 years (Chart 3).

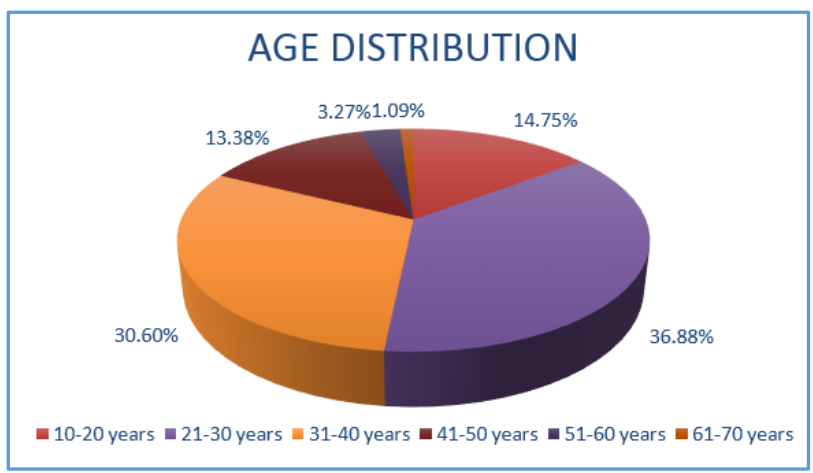

Chart 3. Showing Age Distribution

The most common cause of fractures was Road Traffic Accidents (RTA), which accounted for $78.14 \%$. It was followed by Human or Animal assaults which accounted for $13.11 \%$ and fall from height accounted for $8.74 \%$. Aetiological incidence is shown in Chart 4.

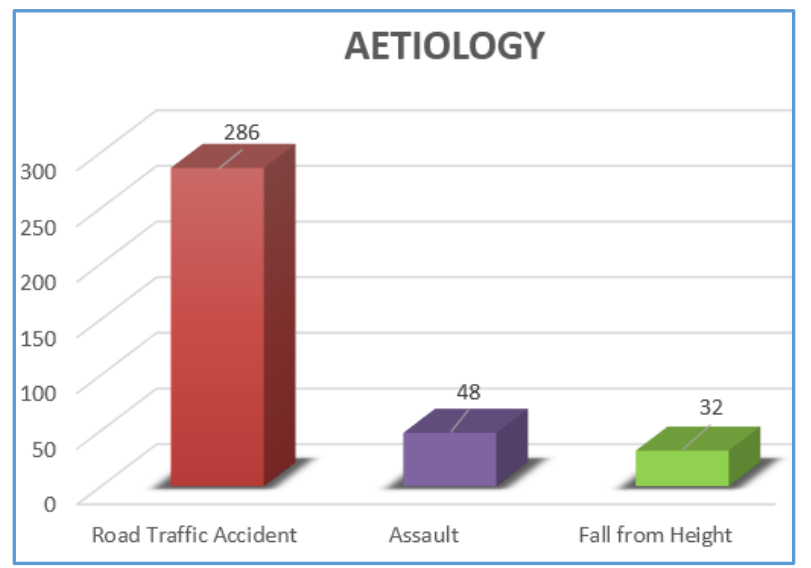

Chart 4. Showing Aetiology 
Alcohol consumption had been a compounding factor for fracture, both RTA and Human assault. ${ }^{8}$

In our study, the most common site of fracture was body of zygoma $(n=122)$ accounting to $33.33 \%$. Next common site was arch of zygoma ( $\mathrm{n}=110)$ cases equating $30.05 \%$ (Chart 5).

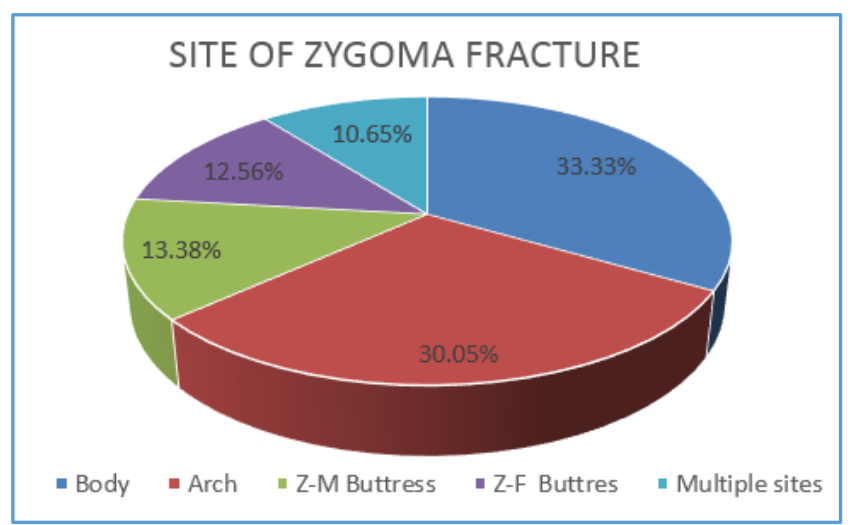

Chart 5. Showing Site of Zygoma Fracture

Then were Zygomaticomaxillary buttress fractures $(n=49)$ at $13.38 \%$ and Zygomaticofrontal buttress fracture $(n=46)$ at $12.56 \%$. Bilateral fractures with various combinations were seen $(n=39)$ in $10.65 \%$ of patients. Right side fractures $(n=201)$ accounted for $54.91 \%$, while those with left side fractures $(n=165)$ amounted to $45.01 \%$ (Chart 6).

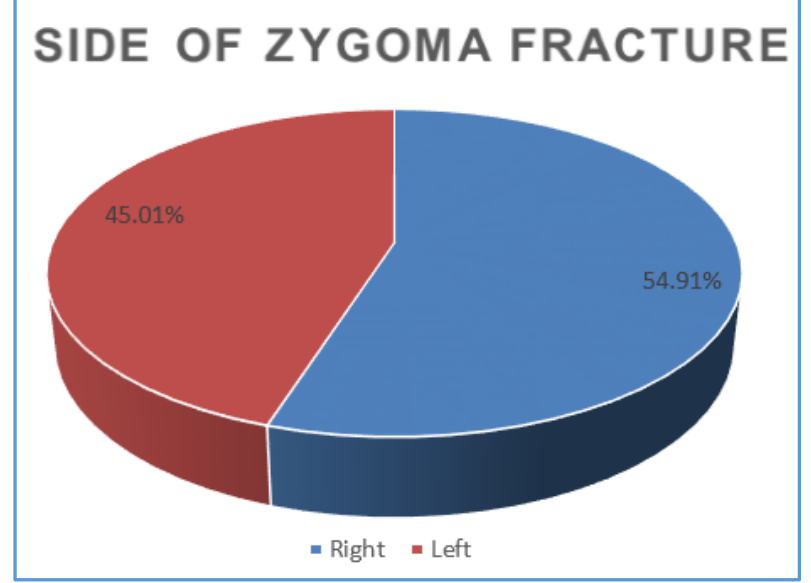

Chart 6. Showing Side of Zygoma Fracture

Methods of fracture reduction of zygoma were by Open Reduction and Internal Fixation (ORIF) in 56.83\%, Gillies' Elevation (Closed Reduction) in $34.15 \%$ and some cases were managed conservatively (9.01\%) as shown in Chart 7.

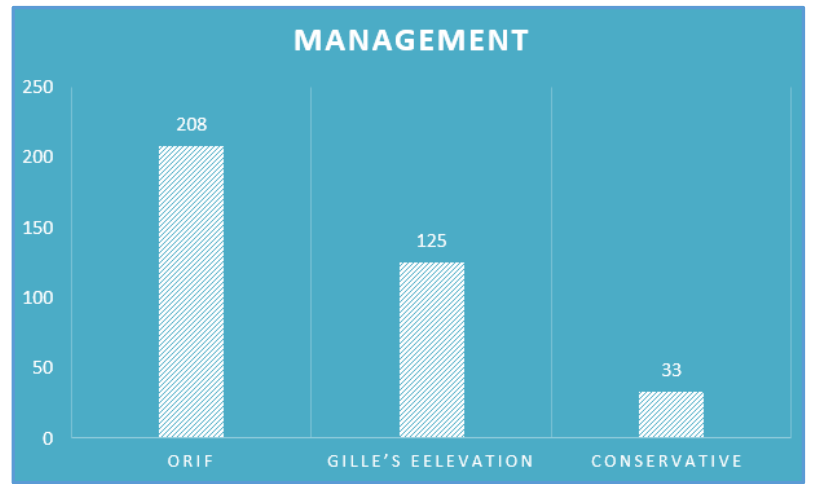

Chart 7. Showing Management

ORIF is usually done using 4 holed plate with gap or 3 holed plate with gap with $1.5 \mathrm{~mm}$ thickness, and either $8 \mathrm{~mm}$ or $10 \mathrm{~mm}$ screws having $1.5 \mathrm{~mm}$ diameter. Closed reduction was by Gillies' elevation. 9,10

In the majority of cases (87.15\%), good mouth opening was achieved and the rest of the patients had some restricted mouth opening who amounted to $12.84 \%$ (Chart 8).

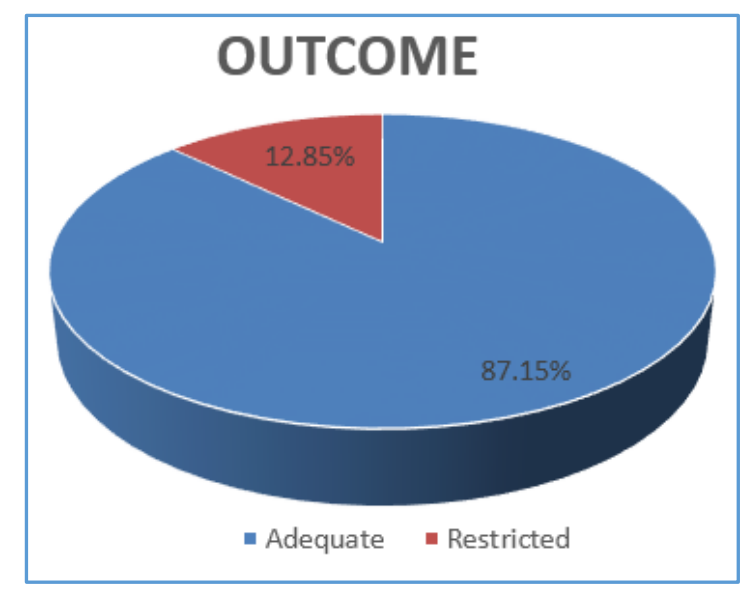

Chart 8. Showing Result of Surgery

Corrective procedures adopted for patients with restricted mouth opening were treated either with redo ORIF (4.91\%) or dilatation with Heister's dilator (5.46\%). Few patients were advised to insert ice cream sticks between the molar teeth $(2.45 \%)$ as shown in Chart 9.

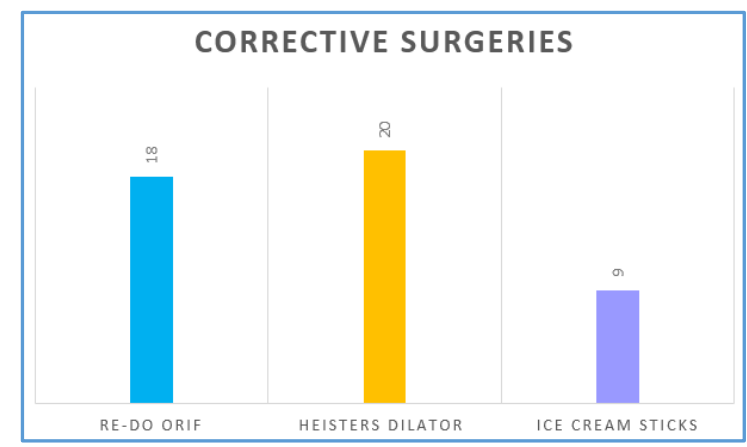

Chart 9. Showing Corrective Surgeries 
We did come across a few complications like wound infection (4.09\%) and implant exposure (2.18\%) was noted (Chart 10).

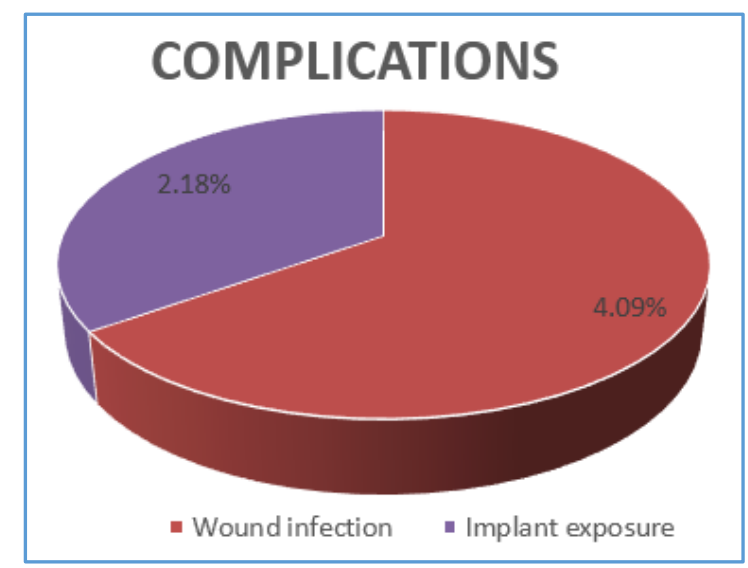

Chart 10. Showing Complications

Those with wound infection were treated with regular dressing and secondary suturing, while those with implant exposure were treated with implant removal and wound closure respectively.

Most of the patients were discharged on the second or third post-operative day and were followed every week in the outpatient department. Patients were advised liquid diet and were told to avoid pressure on operation site and were advised to sleep on non-operated side. Sutures were removed after one week. Adequacy of mouth opening was assessed at every outpatient visit.

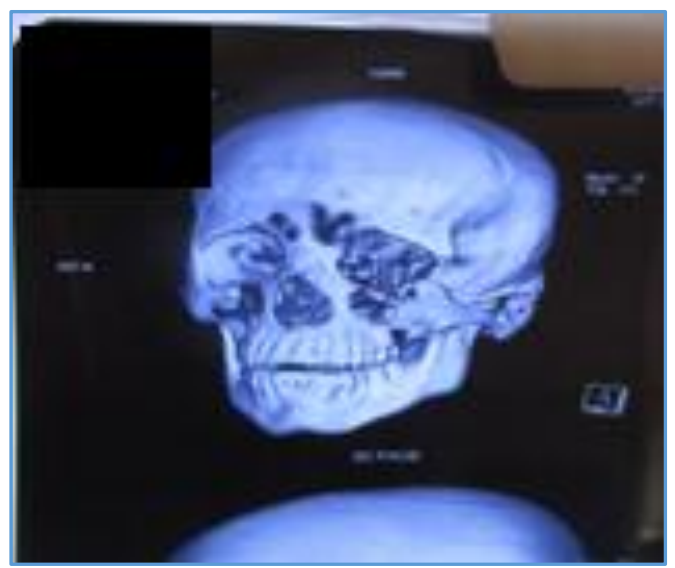

Pre-Op 3D CT Scan

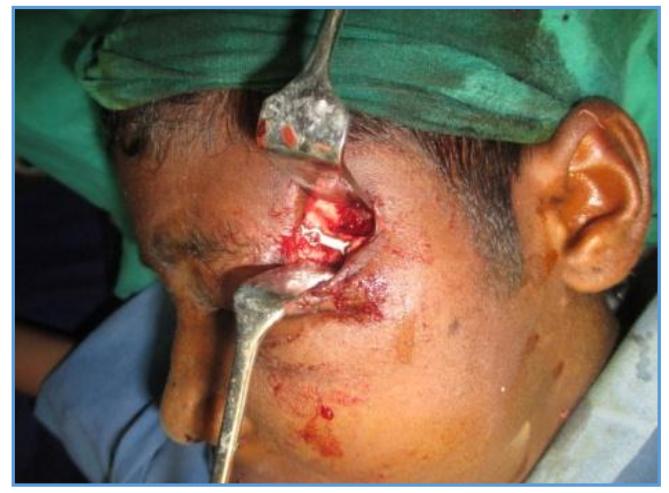

Intra-Op Photo

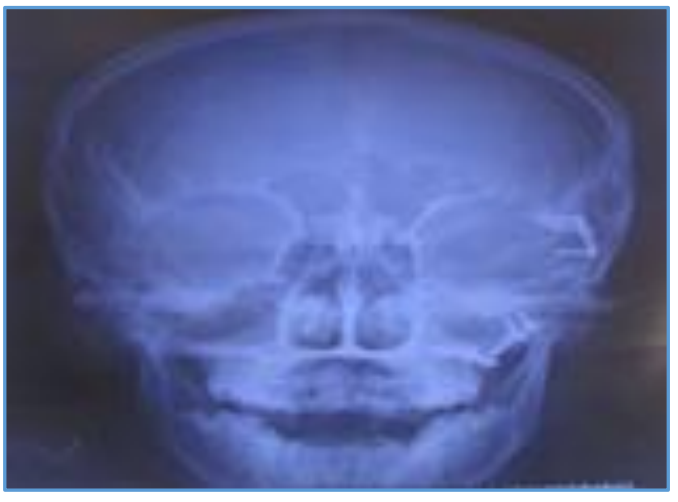

Post-Op X-Ray

\section{DISCUSSION}

With increasing population and urbanisation, in particular in Hyderabad, the capital city of Telangana state in India, road traffic accidents are very common. Unplanned roads, poorly maintained roads, increase in number of vehicles, decreased road area to number of vehicles ratio, busy lifestyle led to increase in road traffic accident. The rise in the motorised population accompanied by rash driving and disregard to traffic rules has resulted in a mercurial rise in RTA resulting in gross injuries.11,12 The most common cause of facial fractures in our study was road traffic accidents. Males were more commonly involved than females. These findings were consistent with findings from other countries. ${ }^{13}$

In this study, diagnosis of fracture was based on clinical examination, x-rays and 3D CT facial bones. Computerised tomography is the most sensitive and specific imaging technique.

The results of our study regarding age, aetiology and management were compared with the studies of Garg Ramneesh, Gupta Gulzar ${ }^{14}$ et al and Ungari ${ }^{15}$ et al.

Most common age group involved in our study was the group between 21 - 30 years. We had 36.88\% involvement in that age group. Similar observation was noticed in the study done by "Ungari et al" where it was $31.9 \%$ and also in the study done by "Suresh Menon et al" where it was $47.88 \%$. However, the study of "Garg Ramneesh, Gupta Gulzar et al showed the highest incidence in the age group between 15 30 years ( $22 \%$ ), unlike that noticed in our study.

Males were most commonly affected (88.9\%) in our study, as is noticed in study by Garg Ramneesh and Gupta Gulzar et al, where it was $83 \%$ and in the study of Ungari et al where it was 88.62 and in the study of Suresh Menon et al was $84.50 \%$.

Most common cause of fracture zygoma in our study was RTA (78.14\%) and the same was noticed in the study done by Garg Ramneesh. In the study done by Gupta Gulzar et al, it was $69 \%$ and in the study of Suresh Menon et al it was $83.56 \%$, while in the study done by Ungari et al it was $26 \%$ only, but still was the leading cause.

Most common method adopted for reduction of fracture zygoma was open reduction and internal fixation (56.83\%) in our study and this similar finding was noted in the study of Garg Ramneesh, Gupta Gulzar et al with 68\%.

Most of the affected patients were from low and middle class income group. Alcoholism was the main culprit for the RTA. Rampant opening of Government run belt shops, wine 
shops along the highways have been found to be the leading cause of accidents.

Patients with reasonably good mouth opening were treated conservatively. We did come across some complications like post-operative oedema, wound infection, restricted mouth opening and implant exposure.

\section{CONCLUSION}

The results of our study indicate that the RTA is the main cause of fractures of zygoma followed by assault. Body of zygoma was the most common site of fracture. Majority of the patients were males aged between 21 and 30 years. Most of the cases were managed with ORIF and many of them achieved good mouth opening.

Government should focus on strict implementation of traffic rules and regulations. People should be educated about the hazards of drunken driving. Police should be trained to enforce the law. The mindset of the people should be modified to the benefit of their family members and for the society at large.

\section{REFERENCES}

[1] Edward E 3rd, Kittidumkerng W. Analysis of treatment for isolated zygomaticomaxillary complex fractures. J Oral Maxillofac Surg 1996;54(4):386-400.

[2] Chowdhury SKR, Menon PS. Etiology and management of zygomaticomaxillary complex fractures in the armed forces. MJAFI 2005;61(3):238-40.

[3] Jelks GW, La Trentra G. Orbital fractures. In: Foster CA, Sherman JE, eds. Surgery of facial bone fractures. 17th edn. New York, NY: Churchill Livingstone 1987: p. 6791.

[4] Menon A, Karikal A, Shetty V. Does C-Arm guidance improve reduction of zygomatic arch fractures? A randomized controlled trial. Journal of Oral Maxillofac Surgery 2018 Jun 1. pii: S0278-2391(18)30501-9.

[5] Lin Q, Hong XY, Zhang D, et al. Preoperative evaluation and surgical technique of functional and cosmetic aspects in zygomatic complex fracture patients. J Biol Regul Homeost Agents 2017;31(4):1005-12.
[6] Nayyar MS. Management of zygomatic complex fracture. J Coll Physicians Surg Pak 2002;12:700-5.

[7] Kiwanuka E, Smith SE, Frates MC, et al. Use of highfrequency ultrasound guidance for intraoperative zygomatic arch fracture reduction. Journal of Craniofaciall Surgery 2013;24(6):2036-8.

[8] Cannell H, Boyd R. The management of maxillofacial injuries in vagrant alcoholics. Journal of Maxillofacial Surgery 1985;13(3):121-4.

[9] Bezuhly M, Lalonde J, Alqahtani $M$, et al. Gillies elevation and percutaneous Kirschner wire fixation in the treatment of simple zygoma fractures: long-term quantitative outcomes. Plast Reconstr Surg 2008;121(3):948-55.

[10] Ehrenfeld M, Mast G, Smith AC, et al. Strohmeyer/Wassmund method of repositioning versus Gillies' elevation. Results of various fracture management concepts of the zygoma. Fortschr Kiefer Gesichtschir 1991;36:96-9. German

[11] Huelke DF, Compton CP. Facial injuries in automobile crashes. J Oral Maxillofac Surg 1983;41(4):241-4.

[12] Iida S, Kogo M, Sugiura T, et al. Retrospective analysis of 1502 patients with facial fractures. Int J Oral Maxillofac Surg 2001;30(4):286-90.

[13] Punjabi SK, Habib-ur-Rehman, Ali Z, et al. Causes and management of zygomatic bone fractures at Abbasi Shaheed Hospital Karachi (analysis of 82 patients). Journal of Pakistan Medical Association 2011;61(1):36-9.

[14] Ramneesh G, Gulzar G, Sanjeev U, et al. A retrospective audit of hundred patients of orbitozygomatic fractures with brain injury. Journal of Clinical and Diagnostic Research 2014;8(7):NC04-NC06.

[15] Ungari C, Filiaci F, Riccardi E, et al. Etiology and incidence of zygomatic fracture: a retrospective study related to a series of 642 patients. Eur Rev Med Pharmacol Sci 2012;16(11):1559-62.

[16] Menon S, Sinha R, Thapliyal G, et al. Management of zygomatic complex fractures in a tertiary hospital: a retrospective study. Journal of Maxillofac Oral Surg 2011;10(2):138-41. 